\title{
In memoriam François Laplanche (1928-2009)
}

Avant-propos

Daniel-Odon Hurel

\section{CpenEdition}

Journals

Édition électronique

URL : http://journals.openedition.org/assr/26173

DOI : $10.4000 /$ assr.26173

ISSN : 1777-5825

Éditeur

Éditions de l'EHESS

Édition imprimée

Date de publication : 20 octobre 2014

Pagination : 173-174

ISBN : 978-2-7132-2433-1

ISSN : 0335-5985

Référence électronique

Daniel-Odon Hurel, « In memoriam François Laplanche (1928-2009) », Archives de sciences sociales des religions [En ligne], 167 | juillet-septembre 2014, mis en ligne le 11 décembre 2014, consulté le 25 avril 2019. URL : http://journals.openedition.org/assr/26173 ; DOI : 10.4000/assr.26173 


\section{In memoriam François Laplanche (1928-2009)}





\section{Daniel-Odon Hurel}

\section{Avant-propos}

En 2010 est paru un important inédit de Loisy, édité et commenté par François Laplanche, avec la collaboration de Rosanna Chiappa, Christoph Theobald et Claude Langlois, La crise de la foi dans le temps présent. Cette publication qui a constitué le volume 144 de la Bibliothèque de l'EPHE chez Brepols a vu le jour un an après le décès de F. Laplanche (2009). Elle est la preuve ultime de la fécondité d'une œuvre étalée sur plus de quarante ans, depuis la thèse de 1975, publiée en 1983 et intitulée Religion, culture et société dans le discours apologétique de la théologie réformée au XVII siècle, jusqu'au volume inédit de Loisy cité plus haut. Durant ces quatre décennies, F. L. s'est inlassablement attaché d'une part à analyser la production des savoirs théologiques, exégétiques et érudits au cœur des débats confessionnels du XVII ${ }^{\mathrm{e}}$ siècle et, d'autre part, à étudier les mutations de l'exégèse catholique $\mathrm{du} \mathrm{XVIII}^{\mathrm{e}}$ au XXe siècle en accordant la place qu'elle méritait à la crise moderniste. Son œuvre ne se limite pas à cette vingtaine de livres car F. L. fut aussi un homme ouvert à ses collègues et aux nombreux étudiants et jeunes chercheurs qu'il eut l'occasion de rencontrer au Laboratoire d'études sur les monothéismes mais aussi à l'École pratique des hautes études, au groupe des historiens de la Bussière et dans les écoles d'été organisées par le Centre européen de recherches sur les congrégations et ordres religieux.

C'est en sa mémoire que s'est tenue, au LEM, le vendredi 10 février 2012, une journée d'étude au cours de laquelle se sont exprimés différents collègues de F. L. dans ses domaines de prédilection, l'historiographie, l'érudition, l'exégèse et la «science catholique ». Parmi ces interventions, sont publiées dans ce volume celles de Dominique Julia, de Claude Langlois (enrichie d'un dossier biographique) et de moi-même. Sont en outre ajoutées au dossier la communication de Jacques Le Brun qui avait souhaité lui conserver son caractère oral et quatre recensions d'ouvrages de F. L. parues dans les ASSR, rédigées par Jean Baubérot, Danièle Hervieu-Léger, Bernard Chédozeau et Pierre Lassave.

L'ensemble de ces textes témoigne de la diversité des lectures possibles de l'œuvre de F. L., une œuvre qui peut être considérée comme «transdisciplinaire ». En effet, elle est l'expression de compétences multiples au service d'une histoire du fait religieux moderne et contemporain profondément enracinée dans une 
anthropologie religieuse et savante d'une part et dans l'analyse approfondie de la Bible et de son statut entre $\mathrm{XVI}^{\mathrm{e}}$ et $\mathrm{XX}^{\mathrm{e}}$ siècles d'autre part.

L'œuvre de F. L. n'est pas ici abordée toute entière, selon une lecture méthodique et systématique. Les éclairages proposés sont autant de lectures individuelles guidées par les préoccupations intellectuelles de chacun : histoire, théologie, histoire de la science catholique, érudition. Ils témoignent cependant de l'intégration permanente des débats exégétiques ou théologiques dans des contextes précis, qu'il s'agisse d'institutions, de confessions religieuses, de milieux spécifiques et ce, dans toute l'Europe, entre XVI et XX ${ }^{\mathrm{e}}$ siècles. En définitive, ces textes insistent particulièrement sur la profondeur historique de la démarche intellectuelle de F. L.

En quelque sorte, F. L., à travers ses travaux, rejoint l'essentiel des questions qui caractérisent, en France en particulier, la crise moderniste et qu'il définit ainsi dans son introduction au Dictionnaire biographique des sciences religieuses (1996) : «le problème des rapports entre l'histoire et la théologie, le statut de la connaissance religieuse, les rapports entre Église, églises et société et enfin la question délicate de la foi et de l'interprétation ». Ces mêmes questions sont tour à tour abordées pour d'autres périodes dans la mesure où elles constituent sans doute l'essentiel des clés de la compréhension de l'histoire du fait religieux dans le christianisme moderne et contemporain. Elles expriment aussi des méthodes d'interrogations nécessaires pour comprendre la transmission et la réception de ces travaux exégétiques, lorsqu'ils sont étudiés dans la pastorale et la prédication.

Daniel-Odon HUREL Laboratoire d'études sur les monothéismes, CNRS, UMR 8584 dohurel@laposte.net 